ARTICLE

DOI: $10.1038 / s 41467-018-05804-2$

\title{
Oxidising agents in sub-arc mantle melts link slab devolatilisation and arc magmas
}

\author{
Antoine Bénard ${ }^{1,2,10}$, Kevin Klimm³ ${ }^{3}$ Alan B. Woodland ${ }^{3}$, Richard J. Arculus ${ }^{1}$, Max Wilke ${ }^{4}$, \\ Roman E. Botcharnikov ${ }^{5,6}$, Nobumichi Shimizu 7 , Oliver Nebel ${ }^{2}$, Camille Rivard ${ }^{8}$ \& Dmitri A. lonov ${ }^{9}$
}

Subduction zone magmas are more oxidised on eruption than those at mid-ocean ridges. This is attributed either to oxidising components, derived from subducted lithosphere (slab) and added to the mantle wedge, or to oxidation processes occurring during magma ascent via differentiation. Here we provide direct evidence for contributions of oxidising slab agents to melts trapped in the sub-arc mantle. Measurements of sulfur (S) valence state in sub-arc mantle peridotites identify sulfate, both as crystalline anhydrite $\left(\mathrm{CaSO}_{4}\right)$ and dissolved $\mathrm{SO}_{4}{ }^{2-}$ in spinel-hosted glass (formerly melt) inclusions. Copper-rich sulfide precipitates in the inclusions and increased $\mathrm{Fe}^{3+} / \sum \mathrm{Fe}$ in spinel record a $\mathrm{S}^{6+}-\mathrm{Fe}^{2+}$ redox coupling during melt percolation through the sub-arc mantle. Sulfate-rich glass inclusions exhibit high U/Th, $\mathrm{Pb} / \mathrm{Ce}, \mathrm{Sr} / \mathrm{Nd}$ and $\delta^{34} \mathrm{~S}(+7$ to $+11 \%$ ) , indicating the involvement of dehydration products of serpentinised slab rocks in their parental melt sources. These observations provide a link between liberated slab components and oxidised arc magmas.

\footnotetext{
${ }^{1}$ Research School of Earth Sciences, The Australian National University, Acton, ACT 2601, Australia. ${ }^{2}$ School of Earth, Atmosphere and Environment, Monash University, Clayton, VIC 3800, Australia. ${ }^{3}$ Institut für Geowissenschaften, Goethe Universität Frankfurt, 60438 Frankfurt am Main, Germany. ${ }^{4}$ Institut für Erd- und Umweltwissenschaften, Universität Potsdam, Karl-Liebknecht-Strasse 24-25, 14476 Potsdam, Germany. ${ }^{5}$ Institut für Mineralogie, Leibniz Universität Hannover, Callinstrasse 3, 30167 Hannover, Germany. ${ }^{6}$ Institut für Geowissenschaften, Gutenberg Universität Mainz, J.-J.-Becher Weg 21, 55128 Mainz, Germany. ${ }^{7}$ Geology and Geophysics Department, Woods Hole Oceanographic Institution, Woods Hole, MA 02543-1052, USA. ${ }^{8}$ European Synchrotron Radiation Facility, Grenoble 38043, France. ${ }^{9}$ Géosciences Montpellier, Université de Montpellier and UMR-CNRS 5243, Montpellier 34095 , France. ${ }^{10}$ Present address: Institute of Earth Sciences, Géopolis, CH-1015 Lausanne, Switzerland. Correspondence and requests for materials should be addressed to A.B. (email: antoine.benard@unil.ch) or to K.K. (email: klimm@em.uni-frankfurt.de)
} 
T he oxidation state of magmas represents the sum of the electron exchange balance between multivalent atoms including major $(\mathrm{Fe})$, minor $(\mathrm{Mn})$, trace $(\mathrm{Cr}$ and $\mathrm{V})$ and volatile $(\mathrm{S}, \mathrm{C}$ and $\mathrm{H})$ elements ${ }^{1}$. The redox conditions, expressed in terms of oxygen fugacity $\left(\mathrm{fO}_{2}\right)$, control the evolution and degassing of magmas in volcanic arcs above subduction zones and the formation of ore deposits ${ }^{2}$. In practice, the $\mathrm{fO}_{2}$ during the generation and evolution of magmas can be estimated on the basis of $\mathrm{Fe}^{3+} / \Sigma \mathrm{Fe}\left(\mathrm{Fe}^{3+} /\left(\mathrm{Fe}^{3+}+\mathrm{Fe}^{2+}\right)\right)$ in quenched melts ${ }^{3}$ and olivinepyroxene-spinel assemblages in crystal-rich rocks ${ }^{4,5}$, or alternatively from $S^{6+} / \Sigma S\left(S^{6+} /\left(S^{6+}+S^{2-}\right)\right)$ in quenched melts ${ }^{6-8}$.

In subduction zones, the $\mathrm{fO}_{2}$ of the different rocks varies over several log units above the fayalite-magnetite-quartz (FMQ) reference buffer assemblage (Fig. 1a). Mid-ocean ridge basalts (MORBs) and abyssal peridotites are representative of the oceanic lithosphere that ultimately undergoes subduction (slab) and are relatively reduced, with $\mathrm{fO}_{2}$ close to and below $\mathrm{FMQ}^{9}$. However, before being subducted, the oceanic lithosphere can be altered and oxidised on or near the seafloor by hydrothermal and metamorphic processes. Arc lavas, generated by interactions between agents derived from the oxidised slab and the relatively reduced mantle wedge, generally display higher $\mathrm{fO}_{2}$ than MORB, with values above FMQ ${ }^{7,10,11}$. Xenoliths from the sub-arc mantle lithosphere (Fig. 1b), sampled as rock fragments in volcanic deposits, record $\mathrm{fO}_{2}$ ranging from FMQ to two log units above $^{12,13}$ (Fig. 1a).

The oxidised nature of arcs compared with mid-ocean ridges has been largely attributed to the addition of volatile-rich slab agents to the asthenospheric mantle source in arcs before or during melting ${ }^{12-16}$. Slab-derived $\mathrm{S}^{6+}$, generally linked with oxygen to form reactive sulfate $\left(\mathrm{SO}_{4}{ }^{2-}\right)$ ions, has been proposed as a key player in mantle wedge oxidation ${ }^{2,16-18}$, as it is a powerful oxidising agent able to convert $8 \mathrm{~mol}$ of $\mathrm{Fe}^{2+}$ into $\mathrm{Fe}^{3+}$ per mole of $\mathrm{S}^{6+}$ according to the reaction:

$$
\mathrm{SO}_{4}^{2-}+8 \mathrm{FeO}<=>\mathrm{S}^{2-}+4 \mathrm{Fe}_{2} \mathrm{O}_{3}
$$

Mounting evidence from stable isotope measurements on deeply subducted rocks ${ }^{15,17,18}$ supports the idea that fluids released from these rocks could be enriched in $\mathrm{SO}_{4}{ }^{2-}$ (Fig. 1b). In parallel, the involvement of slab-derived $\mathrm{S}$ in the generation of arc magmas is supported by $S$ isotope systematics, with elevated $\delta^{34} S$ a

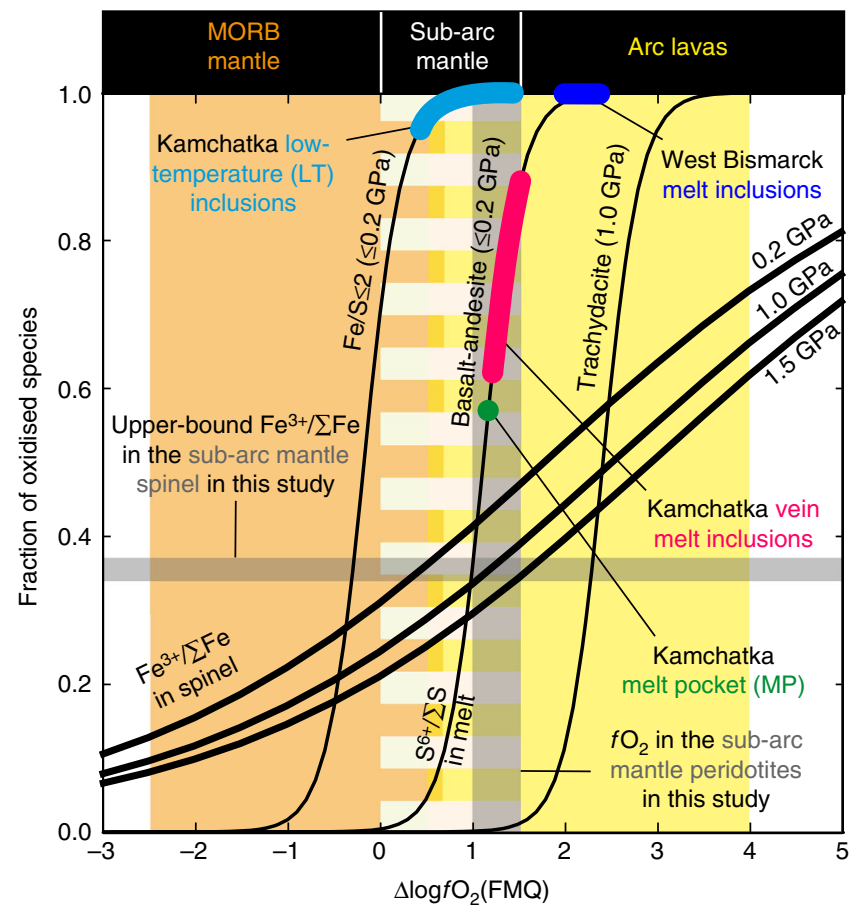

b

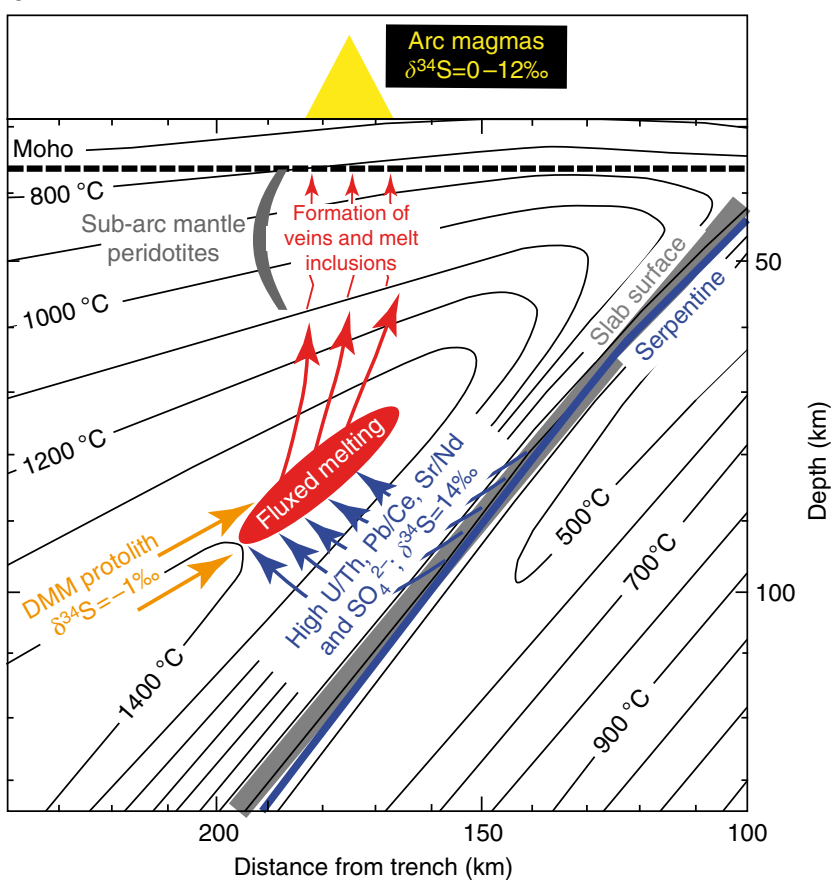

Fig. 1 Sulfur valence state at oxygen fugacities prevailing at mid-ocean ridges and subduction zones and the origins of the glass (formerly melt) inclusions $(\mathrm{MI})$ in Kamchatka and West Bismarck sub-arc mantle peridotites. a $\mathrm{S}^{6+} / \sum \mathrm{S}$ equilibrium (thin black curves) in silicate melts and the range of $\Delta$ logfO $\mathrm{O}_{2}$ measured for subduction zone rocks and melts expressed relative to FMQ: orange, abyssal peridotites (MORB mantle) ${ }^{43,44}$; white bars, sub-arc mantle rocks ${ }^{12,13,34}$; yellow, arc lavas $7,8,11$. The $\mathrm{S}^{6+} / \sum \mathrm{S}$ equilibrium curves are shown for Fe-poor $(\mathrm{Fe} / \mathrm{S} \leq 2)$ and Fe-rich $(\mathrm{Fe} / \mathrm{S} » 2)$ silicate melts at low-pressure $\left(\leq 0.2 \mathrm{GPa}\right.$ ) conditions $\mathrm{s}^{8,16}$ and for $1 \mathrm{GPa} 40$. The $\mathrm{S}^{6+} / \sum \mathrm{S}$ determined by XANES and inferred from Raman spectrometry for Kamchatka LT inclusions, MP, and vein $\mathrm{Ml}$ and West Bismarck $\mathrm{Ml}$ are respectively shown in cyan, green, pink and blue. The upper-bound Fe ${ }^{3+} / \sum \mathrm{Fe}$ in spinel measured by EPMA (i.e., in halos next to the inclusions) for the percolated harzburgite samples Av33 (Kamchatka) and 67-02D(7) (West Bismarck) is indicated with a grey horizontal bar (Supplementary Tables 5 and 6). The range of $\Delta \operatorname{logfO} \mathrm{O}_{2}$ calculated for the percolated harzburgite samples Av33 and 67-02D(7), using the EPMA data on spinel (away from the inclusions and their halos) reported in this study and earlier ${ }^{26,34}$, is indicated with a grey vertical bar (Supplementary Tables 9 and 10). Also shown are the calculated $\mathrm{Fe}^{3+} / \sum \mathrm{Fe}$ in spinel in equilibrium with the parental melts of LT inclusions and MP at $0.2,1$ and $1.5 \mathrm{GPa}$ (bold black curves), using the $\mathrm{Fe}^{3+} / \sum \mathrm{Fe}$ equilibrium in silicate melts ${ }^{3}$ and partitioning coefficients for $\mathrm{Fe}^{3+}$ and $\mathrm{Fe}^{2+}$ between $\mathrm{Cr}_{\text {-bearing spinel and melt }}^{32}$ (Supplementary Table 12). b A subduction zone cross-section showing the original position of the studied peridotite xenoliths ('sub-arc mantle peridotites') from Kamchatka and West Bismarck in the shallow mantle lithosphere before their ascent in arc magmas. Also indicated are the stability fields for subducted serpentine (antigorite, dark blue line) ${ }^{50}$ and the geochemical features of the inferred fluids derived therefrom (dark blue arrows) ${ }^{15,50}$, DMM (orange) 48,49 and erupted arc magmas (yellow triangle) ${ }^{19-21,51}$. The inclusions in this study allow probing the redox conditions in and sulfur isotope compositions of the deep mantle wedge ('fluxed melting', red field) 
in arc melts and volcanic gases interpreted as the result of $\mathrm{S}$ recycling from the slab ${ }^{19-21}$ (Fig. 1b). However, it remains unclear if the released slab fluids are sufficiently abundant and oxidised to travel tens of kilometres to the zones of arc melt generation without being reduced by the ambient mantle (Fig. 1b). Indeed, direct evidence for the presence of recycled, slab-derived sulfate in sub-arc mantle melts sampled at their earliest stages of evolution remains to be found.

The need for identifying such a missing link also stands out, because the oxidised nature of the sources of arc magmas has been disputed on the grounds that the similar $\mathrm{V} / \mathrm{Sc}$ and $\mathrm{Fe} / \mathrm{Zn}$ measured in ridge- and arc-associated basalts may imply comparable $\mathrm{fO}_{2}$ in the magmatic source regions of both tectonic settings ${ }^{22-24}$. A corollary to this interpretation is that the more oxidised nature observed for arc magmas compared to MORB must result from secondary processes occurring during magma ascent $^{22-24}$. Resolution of this problem has global geochemical significance for quantifying mass fluxes of redox-sensitive elements (e.g., Fe and S) through subduction zones and for the origin of related, S-bearing ore deposits ${ }^{2}$.

Here we report $\mathrm{Fe}$ and $\mathrm{S}$ valence state and $\mathrm{S}$ isotope measurements on sub-arc mantle peridotite xenoliths and their spinel-hosted glass (formerly melt) inclusions (MIs) and pockets, which record the in situ oxidation state of primitive arc melts as they ascend to the overlying crust. The results show that large quantities of $\mathrm{S}^{6+}$ are transferred from the slab to magma generation zones in the mantle wedge, and that sulfate contributes to the oxidation of Fe in sub-arc mantle minerals and the formation of magmatic $\mathrm{Cu}$-rich sulfide.

\section{Results}

Samples. The investigated samples are all spinel harzburgite xenoliths from the sub-arc mantle lithosphere; these peridotites record relatively low temperatures ranging from 650 to $1000^{\circ} \mathrm{C}$, as calculated using olivine-spinel thermometry ${ }^{25-27}$ (Fig. 1b). The mantle xenoliths were brought to the surface by recent volcanic activity at the Avacha (samples Av24, Av25 and Av33) and Ritter (sample 67-02D(7)) volcanoes, respectively, located in the Kamchatka (Russia) and West Bismarck arcs (Papua New Guinea) ${ }^{26-29}$.

As originally described in detail in Ionov et al. ${ }^{28}$ and Bénard et al. ${ }^{29}$, Cr-bearing spinel in Kamchatka xenoliths contains glass MIs with compositions spanning andesite-dacite ('LT inclusions', where LT stands for low temperature), magnesian andesite (melt pockets, 'MP') and dacite-rhyolite of boninitic affinity ('vein MIs'). Spinel in West Bismarck xenoliths contains magnesian andesite glass ('West Bismarck MIs', Supplementary Fig. 1). The $\mathrm{Mg} \#\left(\mathrm{Mg} /\left(\mathrm{Mg}+\mathrm{Fe}_{\mathrm{t}}\right)\right.$, where $\mathrm{Fe}_{\mathrm{t}}$ means all Fe is treated as $\left.\mathrm{Fe}^{2+}\right)$ of the inclusion glasses is generally $\geq 0.6$ in $\mathrm{MP}$, vein $\mathrm{MI}$ and West Bismarck MI but is $<0.4$ in LT inclusions (Supplementary Table 1). High concentrations of slab agents in the inclusion parental melts were inferred from lithophile trace element signatures and very high volatile abundances in the glasses ${ }^{28-31}$; the second compositional feature (e.g., up to $\sim 10 \mathrm{wt} \% \mathrm{H}_{2} \mathrm{O}$ and $\sim 1 \mathrm{wt} \% \mathrm{CO}_{2}$, ref. 29) also indicates that melt entrapment occurred at high pressure in the sub-arc mantle lithosphere (Fig. 1b). The inclusion parental melts are 'exotic' liquids (i.e., they were trapped on their way to the surface and not formed in situ), which were confined in spinel in the sub-arc mantle lithosphere during a percolation process, either pervasive (LT inclusions, MP and West Bismarck MI) or along channels (vein MI ${ }^{28,29}$ (Figs. 1b and 2a). More detail on the spinel-hosted MI investigated in this study is provided in the Supplementary Discussion.

In contrast with earlier works on Kamchatka inclusions ${ }^{28-31}$, we have not used experimentally treated (i.e., heated) MI and their host spinel grains to investigate $\mathrm{S}$ and $\mathrm{Fe}$ valence states in this study. This choice was made considering the possibility of an $\mathrm{Fe}^{3}$ ${ }^{+}-\mathrm{Fe}^{2+}$ exchange reaction during experiment between melt and spinel, in which $\mathrm{Fe}^{3+}$ is compatible ${ }^{32}$, or $\mathrm{Fe}^{3+}$ oxidation in melt triggered by $\mathrm{H}^{+}$loss from the inclusions through either diffusion ${ }^{33}$ or leakage. Instead of using treated MI, we have investigated unheated inclusions that are found naturally free of daughter silicate phases ${ }^{28,29}$ (Supplementary Figs 2-4 and Discussion).

Sulfur abundances and valence state. The full dataset supporting this study is given in Supplementary Tables 1-13. Micro X-ray fluorescence (XRF) mapping combined with micro X-ray absorption near-edge structure (XANES) spectroscopy show that sulfur is heterogeneously distributed in LT inclusions and vein MI, while MP have more homogeneous $S$ concentrations (Fig. 2a-d). The 'bulk' glasses in Kamchatka and West Bismarck MI contain 150-6000 p.p.m. S (Supplementary Tables 1-3). The molar $\mathrm{Fe} / \mathrm{S}$ of the inclusion glasses, an important feature regarding $\mathrm{S}$ dissolution mechanism in hydrous silicate melts ${ }^{16}$, mostly ranges from 8 to 20 in MP, vein MI and West Bismarck MI, but only from 1 to 2 in LT inclusions (Supplementary Tables 1-3).

All spinel-hosted inclusions contain $\mathrm{S}^{6+}$ present as $\mathrm{SO}_{4}{ }^{2-}$ within the glass structure (Fig. $2 \mathrm{e}-\mathrm{g}$ ). The LT inclusions contain almost solely $S^{6+}$ in the glass $\left(S^{6+} / \Sigma S\right.$ always close or equal to 1$)$ and often exhibit the contribution of $\mathrm{S}^{6+}$ from crystalline anhydrite $\left(\mathrm{CaSO}_{4}\right.$, Fig. 2d and Supplementary Fig. 5). The MP glass contains a homogenous mixture of dissolved $S^{6+}$ and $S^{2-}$ with $S^{6+} / S S \sim 0.57$ (Fig. 2e). In addition to $S^{6+}$, some XANES spectra of vein $\mathrm{MI}$ indicate the presence of $\mathrm{S}^{2-}$ that is heterogeneously distributed as a S-bearing solid phase (i.e., an immiscible sulfide, Fig. 2d, g and Supplementary Fig. 5). Depending on the contribution of the immiscible sulfide to the overall XANES spectral measurement, the calculated $S^{6+} / \Sigma S$ for 'bulk' vein MI are variable and can be as low as $0.24-0.44$ (Fig. 2d, $\mathrm{g}$ and Supplementary Fig. 5). The highest $S^{6+} / \Sigma S$ for vein MI range from 0.62 to 0.88 in glassy areas displaying a more homogeneous $\mathrm{S}$ distribution (Fig. 2d, g and Supplementary Fig. 5), which indicate the presence of dissolved $S^{2-}$ in the glass of these inclusions as well. Further characterisation of multiple inclusions using Raman spectrometry reveals that anhydrite is systematically present in LT inclusions (Fig. 2h) and West Bismarck MI (Fig. 2i).

Imaging and mapping. The presence of sub-micrometre anhydrite crystals in LT inclusions and West Bismarck MI is one of the most important results of this study and is further documented by imaging and mapping using electron probe micro-analysis (EPMA) and scanning electron microscope (SEM) techniques (Supplementary Figs 2-4). Although not evidenced by any XANES measurement, rare sulfide blebs sometimes occur in LT inclusions (Supplementary Figs 2-4, 6 and 7). An important observation is that these sulfides may contain as much as $20 \mathrm{wt} \%$ $\mathrm{Cu}$ (Supplementary Table 4).

Iron valence state. Measurements of Fe valence state in the MIhosting spinel using EPMA calibrated with secondary $\left(\mathrm{Fe}^{3+}, \mathrm{Fe}^{2+}\right)$-bearing spinel standards ${ }^{4}$ reveal $\mathrm{Fe}^{3+}$ zoning in irregular halos ${ }^{28}$ next to the inclusions (Fig. 3a-d and Supplementary Tables 5-7). The highest $\mathrm{Fe}^{3+} / \sum \mathrm{Fe}$ in spinel is found adjacent to anhydrite-bearing inclusions and decreases away from the MI, typically from 0.34 to 0.30 and 0.33 to 0.27 for LT inclusions and West Bismarck $\mathrm{MI}^{34}$, respectively (Fig. $3 \mathrm{~d}$ and Supplementary Tables 5 and 6). The halos are also characterised by significantly lower $\mathrm{Cr}$ and higher $\mathrm{Al}$ concentrations (by up to 
a

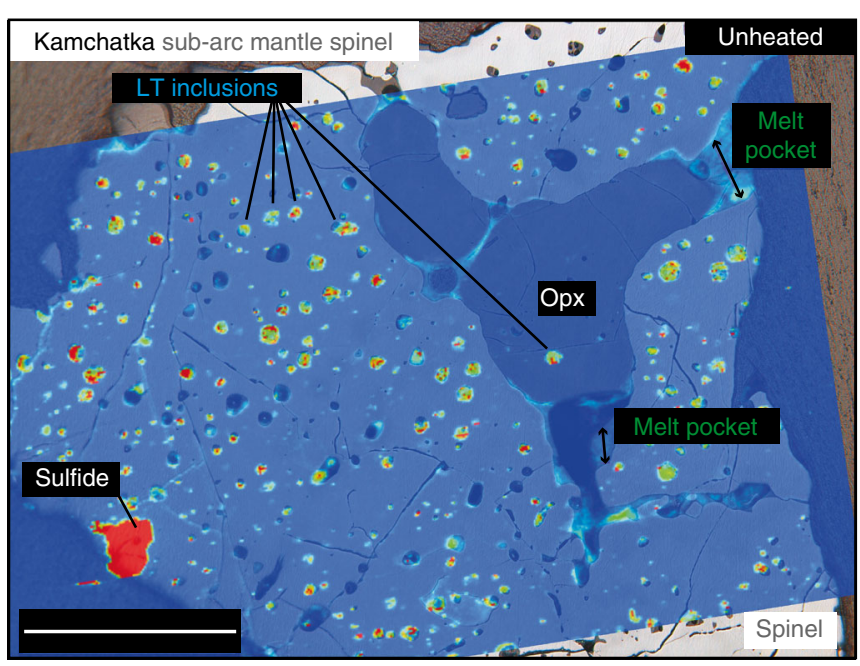

e

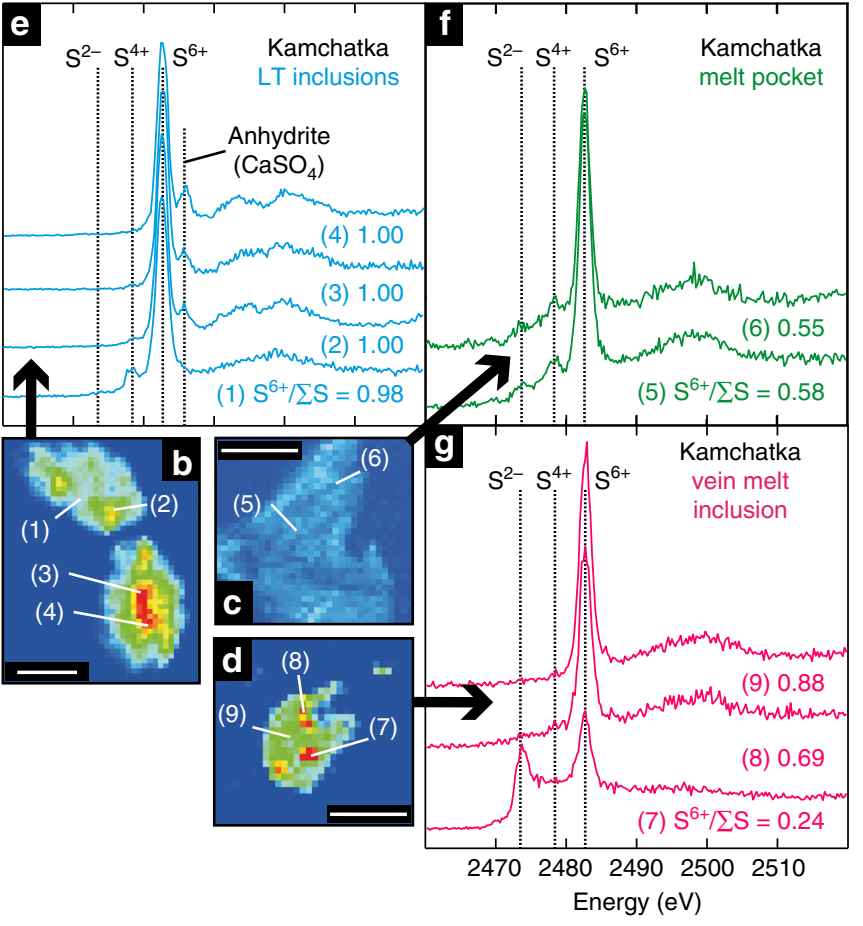

i

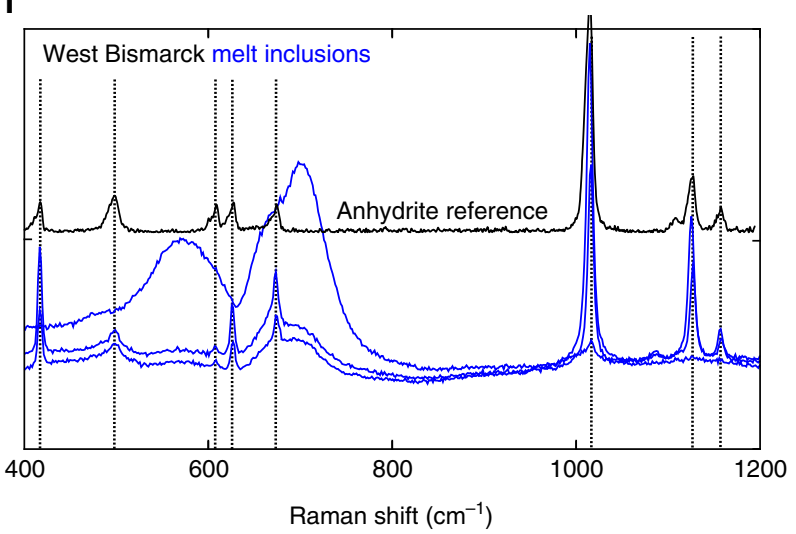

Fig. 2 Spinel-hosted glass (formerly melt) inclusions (MI) from the mantle lithosphere beneath the Kamchatka and West Bismarck arcs and their sulfur distribution and valence state. a A reflected-light image of a spinel grain containing many LT inclusions and MP. Coloured inlay in a shows the elemental distribution of $\mathrm{S}$ in the spinel, LT inclusions and MP determined by $\mathrm{S} \mathrm{K \alpha} \mathrm{X}$-ray fluorescence imaging (red, high $\mathrm{S}$ concentration; blue, low $\mathrm{S}$ concentration). Note the presence of a LT inclusion in an orthopyroxene (Opx) from the host harzburgite, which supports the formation of these inclusions by pervasive percolation of their parental melts in the sub-arc mantle lithosphere. Scale bar length is $\sim 200 \mu \mathrm{m}$. b-d Uncalibrated S K $\alpha$ X-ray fluorescence maps of b LT inclusions, c MP and $\mathbf{d}$ vein MI. The LT inclusions and vein MI are characterised by a heterogeneous distribution of sulfur. The S-free spinel appears in dark blue. Scale bar lengths are respectively $\sim 10 \mu \mathrm{m}$ in $\mathbf{b}$ and $\sim 20 \mu \mathrm{m}$ in c, d. e-g S K-edge XANES spectra of e LT inclusions, $\mathbf{f ~ M P ~ a n d ~} \mathbf{g}$ vein MI. Spectra numbers refer to the spot positions shown in b-d. Vertical black lines indicate energies for specific $\mathrm{S}$ valence states: $2482.8 \mathrm{eV}$ for $\mathrm{S}^{6+}, 2478 \mathrm{eV}$ for $\mathrm{S}^{4+}$ and $2472.5 \mathrm{eV}$ for $\mathrm{S}^{2-}$ in crystalline Fe-S compounds. The additional feature at $2486 \mathrm{eV}$ is typical for crystalline anhydrite $\left(\mathrm{CaSO}_{4}\right)$. Some $\mathrm{S}^{4+}$ is generated during XANES measurements of glasses by photo-reduction of $\mathrm{S}^{6+}$. The LT inclusions contain solely $\mathrm{S}^{6+}$ in glass and in anhydrite. The MP contain $\mathrm{S}^{2-}$ and $\mathrm{S}^{6+}$ in glass with $0.55 \leq \mathrm{S}^{6+} / \sum \mathrm{S} \leq 0.58$. The vein MI dominantly contain $\mathrm{S}^{6+}$ in the glass with $\mathrm{S}^{6+} / \sum \mathrm{S}$ up to 0.88 but also show varying contributions of $\mathrm{S}^{2-}$ from immiscible sulfides (Supplementary Table 1). $\mathbf{h}$, i Raman spectra for $\mathbf{h}$ multiple LT inclusions and an MP, and $\mathbf{i}$ West Bismarck MI, compared with their host spinel (grey spectrum) and an anhydrite $\left(\mathrm{CaSO}_{4}\right)$ reference (black spectrum). All these inclusions, with the exception of the MP, contain anhydrite. Note that all the inclusions for which data are presented here are unheated

0.10-0.25 At\%), but comparatively little variations in $\mathrm{Fe}^{2+}, \mathrm{Mg}$ and $\mathrm{Mg \#}$ (by only 0.01-0.04) than in spinel away from the inclusions (Supplementary Tables 5 and 6); these halos are very similar to those around MP reported by Ionov et al. ${ }^{28}$ (Supplementary Fig. 8 and Supplementary Table 8). Further EPMA measurements reveal that the $\mathrm{Fe}^{3+} / \sum \mathrm{Fe}$ increase can be also restricted to the LT inclusion-bearing rims of some spinel grains that are only partially impregnated with melt (Supplementary Fig. 7 and Supplementary Table 5).
Oxygen fugacity estimates. The $\mathrm{fO}_{2}$ values (expressed as the deviation from FMQ in $\log$ units, $\Delta \log f \mathrm{O}_{2}$ ) inferred from the $S^{6}$ $+/ \Sigma \mathrm{S}$ equilibrium in 'Fe-poor' silicate melts $(\mathrm{Fe} / \mathrm{S} \leq 2)$ at $\leq$ $0.2 \mathrm{GPa}^{16}$ range from FMQ +0.5 to $\mathrm{FMQ}+1.5$ for LT inclusions. The $\Delta \log f \mathrm{O}_{2}$ values inferred from the $S^{6+} / \Sigma S$ equilibrium in 'Fe-rich' silicate melts $(\mathrm{Fe} / \mathrm{S} » 2)$ at $\leq 0.2 \mathrm{GPa}^{8,16}$ range from FMQ +1 to $\mathrm{FMQ}+1.5$ for MP and vein MI, and correspond to ca. FMQ +2 for West Bismarck MI (Fig. 1a). It is noteworthy that as anhydrite saturation is evidenced in all LT inclusions and West 


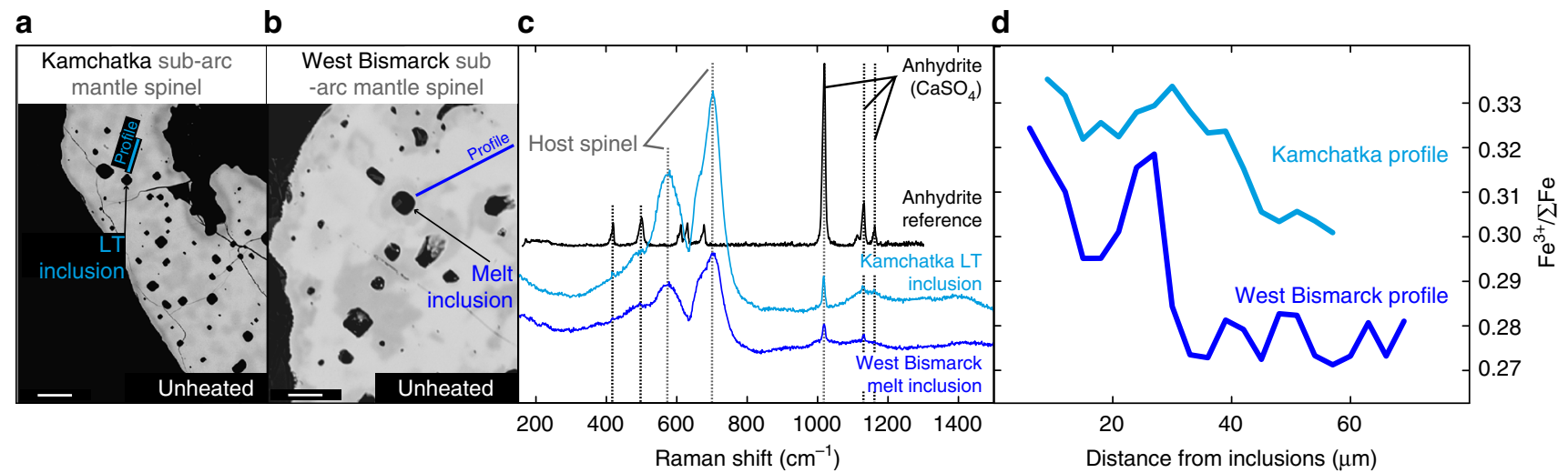

Fig. 3 Coexisting anhydrite in glass (formerly melt) inclusions (MI) and increased ferric iron abundances in their host spinel from the mantle lithosphere beneath Kamchatka and West Bismarck arcs. Back-scattered electron (BSE) images of chemical zoning (halos) of a Kamchatka and $\mathbf{b}$ West Bismarck inclusion-bearing mantle spinel. Scale bar lengths are respectively $\sim 50 \mu \mathrm{m}$ in $\mathbf{a}$ and $\sim 20 \mu \mathrm{m}$ in $\mathbf{b}$. c Raman spectra of the inclusions (LT inclusions and West Bismarck $\mathrm{MI})$ in $\mathbf{a}$, b plus an anhydrite $\left(\mathrm{CaSO}_{4}\right)$ reference (black spectrum). $\mathbf{d}$ Measured $\mathrm{Fe}^{3+} / \sum \mathrm{Fe}$ profiles in spinel adjacent to the inclusions indicated with lines in $\mathbf{a}, \mathbf{b}$. The variable contrast of spinel visible in the BSE images in $\mathbf{a}$, $\mathbf{b}$ is related to changes in the concentrations of $\mathrm{Al}, \mathrm{Cr}, \mathrm{Fe}$ and $\mathrm{Mg}$ in irregular halos surrounding anhydrite-bearing MI (Supplementary Tables 5 and 6 ). Note that all inclusions for which data are presented here are unheated

Bismarck MI investigated in this study (Fig. 2e, h, i and Supplementary Fig. 5), the $\Delta \log f \mathrm{O}_{2}$ inferred from the $\mathrm{S}^{6+} / \Sigma \mathrm{S}$ equilibrium for these inclusions may constitute only lower-bound estimates. Calculations at $1.5 \mathrm{GPa}$ with a thermometer ${ }^{5}$ and an oxybarometer $^{9}$ for the MI-bearing harzburgite samples, using the stable compositions of spinel measured away from the inclusions and their halos ${ }^{34}$ (Supplementary Tables 5 and 6) and those of coexisting silicate minerals previously reported by Bénard et al. ${ }^{26}$, yield $\Delta \log \mathrm{fO}_{2}$ ranging from FMQ +1.0 to FMQ $+1.4( \pm 0.2-0.3$, Fig. 1a and Supplementary Tables 9 and 10).

Sulfur isotope compositions. From the absence of an immiscible S-bearing phase, and the homogeneous elemental distribution and valence state of $S$ dissolved in their glasses (Fig. 2c, f), it appears that MP are the best suited for the determination of pristine $\delta^{34} S$ using secondary ion mass spectrometry (SIMS). Furthermore, the other types of inclusions are much smaller than MP in $\operatorname{size}^{28}$ (Fig. 2a), which render SIMS analysis very difficult. We have further selected bubble-free MP found in the harzburgite spinel for these measurements. The $\delta^{34} S$ (see Methods for the usage of delta notation) measured by SIMS ranges from +7 to $+11 \%( \pm 1-1.6,2 \sigma)$ in the glass of MP (Supplementary Table 11).

\section{Discussion}

Before interpreting further the origins of elevated $\mathrm{fO}_{2}$ in sub-arc mantle melts and harzburgites, it should be considered if postentrapment processes affected this feature in the studied inclusions or not. One of these processes is $\mathrm{H}_{2}$ loss from the inclusions, which can displace the equilibrium:

$$
2 \mathrm{FeO}+\mathrm{H}_{2} \mathrm{O}<=>\mathrm{Fe}_{2} \mathrm{O}_{3}+\mathrm{H}_{2}
$$

to the right side as $\mathrm{H}_{2} \mathrm{O}$ dissociates according to:

$$
\mathrm{H}_{2} \mathrm{O}<=>\mathrm{H}_{2}+1 / 2 \mathrm{O}_{2}
$$

and $\mathrm{H}_{2}$ escapes from the system. The very low totals of EPMA analyses in Kamchatka MI (down to $88 \mathrm{wt} \%$ for LT inclusions, 98 $\mathrm{wt} \%$ for MP and $92 \mathrm{wt} \%$ for the vein MI, Supplementary Table 1) indicate bulk volatile contents close to the maximum $\mathrm{H}_{2} \mathrm{O}$ abundances previously determined by SIMS analysis, with up to $\sim 12 \mathrm{wt} \%$ and $\sim 3 \mathrm{wt} \%$, respectively, in LT inclusions and MP ${ }^{30,31}$, and $\sim 10 \mathrm{wt} \% \mathrm{H}_{2} \mathrm{O}$ in the vein $\mathrm{MI}^{29}$. The EPMA setup used in this study has been previously demonstrated to provide deficiency of totals of analyses in good agreement with SIMS volatile data ${ }^{29}$. Therefore, the inclusions in this study are among the most volatile-rich identified in these sub-arc mantle xenoliths so far and, as such, unlikely suffered appreciable $\mathrm{H}_{2} \mathrm{O}$ loss.

Insignificant $\mathrm{H}_{2} \mathrm{O}$ loss from the inclusions is further suggested by the fact that solid-state diffusion of $\mathrm{H}^{+}$within spinel is also two to three orders of magnitude slower than in olivine $^{35,36}$. With the relatively low temperatures recorded in the percolated harzburgites in this study $\left(950-1020^{\circ} \mathrm{C}\right.$, Supplementary Table 10) and prevailing in the shallow mantle below the Kamchatka and West Bismarck arcs ${ }^{25-27}, \mathrm{H}^{+}$diffusivities of $\leq 10^{-14} \mathrm{~m}^{2} \mathrm{~s}^{-1}$ are expected in spinel ${ }^{36}$. Only $30 \mathrm{~min}$ were inferred for the ascent from the sub-arc mantle of West Bismarck peridotite xenoliths from the same sampling sites as in this study ${ }^{37}$. Several hours have been calculated for the ascent of mantle xenolith-bearing magmas at convergent margins with thicker continental crust ${ }^{38}$, such as is the case for the Kamchatka arc. We conclude that volatile loss has not significantly affected the $\mathrm{H}_{2} \mathrm{O}$-rich inclusions during the fast ascent of the xenoliths to the surface.

The calculated $\mathrm{fO}_{2}$ for the inclusions and their host harzburgites in this study fall within the range typically observed for subduction zone lavas and mantle rocks, respectively (Fig. 1a). All $\Delta \log \mathrm{O}_{2}$ estimated above for the inclusions may be shifted even further up if one considers that increasing pressure has a significant effect on the $\mathrm{S}^{6+} / \Sigma S$ equilibrium in silicate melts ${ }^{39,40}$. However, quantifying this pressure effect remains difficult in the present state of knowledge, as it likely interplays in a complex way with those imposed by the variations in melt composition (e.g., Fe/S, ref. ${ }^{16}$ ). For instance, Moretti and Baker ${ }^{39}$ have modelled a shift of the $S^{6+} / \Sigma S$ equilibrium of only ca. $+0.5 \log$ units in $\mathrm{fO}_{2}$ for hydrous tholeite melts, whereas Matjuschkin et al. ${ }^{40}$ have experimentally inferred a shift of ca. $+1.5 \log$ units for hydrous trachydacite melts (Fig. 1a), both with a pressure increase of $\sim 1 \mathrm{GPa}$.

The magnitude of the pressure effect on the $S^{6+} / \Sigma S$ equilibrium for the inclusions in this study can be tested independently using the $\mathrm{Fe}^{3+} / \sum \mathrm{Fe}$ equilibrium in silicate melts ${ }^{3}$ and the experimentally determined partitioning coefficients for $\mathrm{Fe}^{3+}$ and $\mathrm{Fe}^{2+}$ between Cr-bearing spinel and melt $^{32}$. The upper-bound $\mathrm{Fe}^{3+} / \Sigma \mathrm{Fe}$ measured in sub-arc mantle spinel adjacent to the MI (0.34-0.37, Supplementary Tables 5 and 6), correspond to those 
a

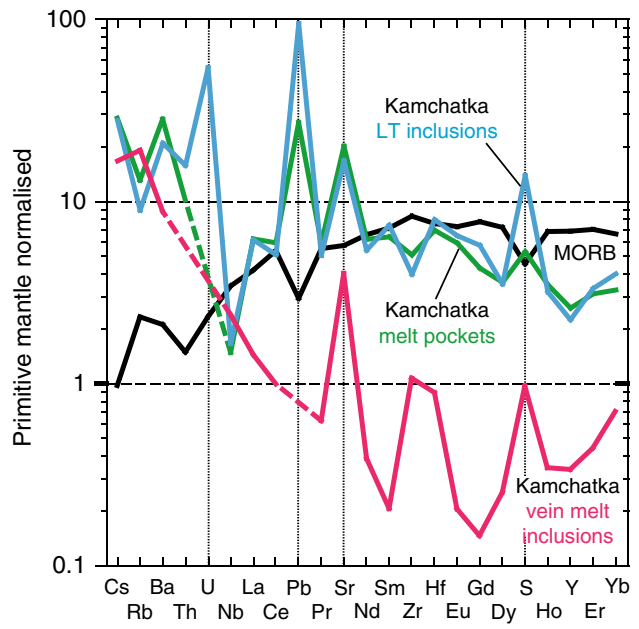

b

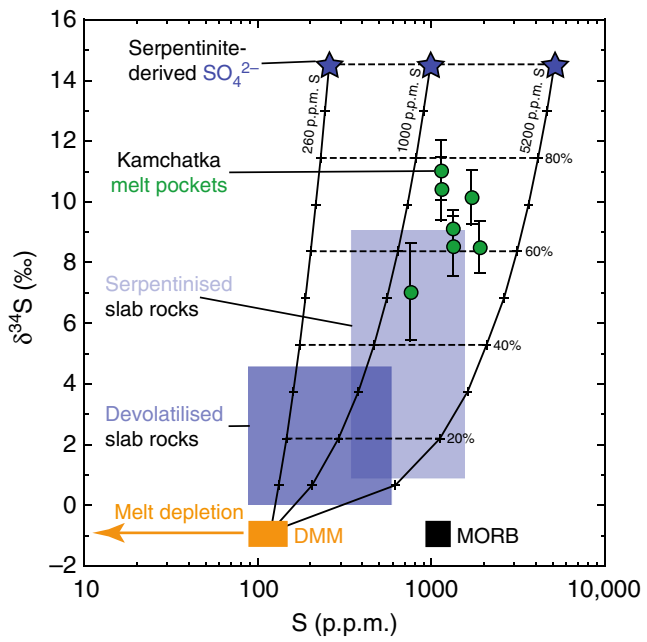

Fig. 4 Lithophile trace element and sulfur isotopic compositions of the studied glass (formerly melt) inclusions. a Primitive mantle-normalised ${ }^{66}$ lithophile trace element abundances (averages, Supplementary Table 13) in the glasses ${ }^{28,29}$ of Kamchatka LT inclusions (cyan pattern), MP (green pattern) and vein MI (pink pattern) compared to MORB $46,48,49$ (black pattern). Sulfur is always enriched in comparison with lithophile trace elements as incompatible as $\mathrm{S}^{2-}$ (e.g. Dy, ref. ${ }^{67}$ ) in the inclusion glasses. This further suggests that $S$ was enriched and/or oxidised in the mantle sources of the inclusion parental melts, since $\mathrm{S}^{6+}$ is much more soluble than $\mathrm{S}^{2-}$ in silicate liquids ${ }^{8,58}$. b A $\delta^{34} S(\%)$ vs. $S$ content (p.p.m.) plot for MP in this study (green dots, Supplementary Table 11), compared with DMM estimates $46,48,49$ (orange field) and MORB data 48,49 (black field). The error bars represent the $2 \sigma$ analytical uncertainty on the $\delta^{34} \mathrm{~S}$ values reported in this study (Supplementary Table 11). Also shown are high-pressure slab rocks ${ }^{15}$ (light and dark blue fields) and black mixing lines between a DMM source and agents derived from subducted serpentinite (dark blue stars), as inferred from high-pressure slab rocks ${ }^{15}$, with variable bulk $S$ contents (260-5200 p.p.m., exclusively present as sulfate). These variable bulk $S$ contents are calculated to account for different dilution factors of $S$ in agents derived from subducted serpentinite, depending on whether these agents contain only $\mathrm{H}_{2} \mathrm{O}$ and S (5200 p.p.m. S) or more components ( $<5200$ p.p.m. S). For this purpose, $\mathrm{H}_{2} \mathrm{O}$ (5 wt\%) and S (260 p.p.m.) abundances inferred to be lost by subducted serpentinite ${ }^{15}$ are used. The composition of the volatile fraction in the parental melts of MP ( $\mathrm{S}$ abundances and $\left.\delta^{34} \mathrm{~S}\right)$ is consistent with mixing between DMM and subducted serpentinite-derived agents containing $\geq 1000$ p.p.m. sulfate $\left(\mathrm{SO}_{4}{ }^{2-}\right)$. Given that the mantle source protoliths of the MP parental melts are more depleted than DMM (a), 1000 p.p.m. $\mathrm{S}$ in agents derived from subducted serpentinite likely represents a lower bound and the mixing lines could be shifted to the left in $\mathbf{b}$ ('melt depletion', orange arrow). Note that all MP for which $\mathrm{S}$ data are presented here are unheated

calculated for $\Delta \log f \mathrm{O}_{2}$ ranging from $\mathrm{FMQ}+1$ to $\mathrm{FMQ}+1.5$ at 1-1.5 GPa in spinel in equilibrium with the parental melts of LT inclusions and MP (Fig. 1a and Supplementary Table 12). As this $\Delta \log f \mathrm{O}_{2}$ range corresponds well to the results of oxybarometric calculations for the host sub-arc mantle harzburgites in this study (Fig. 1a and Supplementary Table 10), we conclude that it constitutes the best estimate for the formation of their inclusions. Furthermore, the calculated $\mathrm{Fe}^{3+} / \Sigma \mathrm{Fe}$ in spinel provides additional evidence that the formation of the inclusions occurred at $\geq$ $1 \mathrm{GPa}$, i.e., in the sub-arc mantle (Fig. 1a, b). This test based on our EPMA data does not preclude an effect of pressure on the $\mathrm{S}^{6+} / \Sigma \mathrm{S}$ equilibrium in silicate melts, but rather suggests that it is within the error of the $\Delta \log f \mathrm{O}_{2}$ estimates (typically \pm 0.5 , Supplementary Table 10) for the samples in this study.

In situ observations demonstrate that sulfate is present in melts from the mantle below the Kamchatka and West Bismarck arcs, recording $\Delta \log f \mathrm{O}_{2}$ of at least ca. FMQ +1 (Fig. 1a). The mantle source protoliths (i.e., considered before fluxing by slab agents occurs in the mantle wedge, Fig. 1b) of the inclusion parental melts must be more depleted than the MORB source mantle (DMM), as inferred from their relatively low heavy and middle rare-earth element and $\mathrm{Y}$ abundances ${ }^{28,29}$ (Fig. 4a). For instance, $\sim 15 \%$ melt extraction from DMM was calculated for the mantle source protoliths of the boninitic parental melts of the vein $\mathrm{MI}^{29}$. Studies of primary MORB show that these magmas are equilibrated in their sources at $\mathrm{FMQ}^{41,42}$, whereas the $\mathrm{fO}_{2}$ of abyssal peridotites dominantly ranges below $\mathrm{FMQ}^{43,44}$ (Fig. 1a). Therefore, it is unlikely that the original $f \mathrm{O}_{2}$ is higher than FMQ in the more depleted mantle source protoliths of the inclusion parental melts in this study, owing to the preferential decrease in $\mathrm{Fe}^{3+}$ concentrations and $\mathrm{Fe}^{3+} / \Sigma \mathrm{Fe}$ in the mantle with increasing melt depletion ${ }^{32,34,45}$.
Furthermore, 15\% melting of a DMM source containing 90-150 p.p.m. S (ref. ${ }^{46}$ ) and the formation of a basalt dissolving $\geq 1000$ p.p.m. $S$ at $\leq 1.5 \mathrm{GPa}$ and $\geq 1200^{\circ} \mathrm{C}$ (ref. ${ }^{47}$ ) is also unlikely to leave significant amounts of residual sulfides. However, all inclusion types in this study are particularly enriched in S and other volatiles ${ }^{29-31}$ (Fig. 4a, Supplementary Tables 1-3 and Discussion). The high $\delta^{34} \mathrm{~S}$ measured in the MP are not intrinsic to the upper Earth's mantle such as $\mathrm{DMM}^{48,49}$, but are inevitably related to recycled components (Fig. $4 \mathrm{~b}$ ). It has been recently shown that subducted serpentinite is a possible carrier of large amounts of sulfate with elevated $\delta^{34} S$ to sub-arc mantle depths $s^{15,17,18}$. A contribution from subducted serpentinite is further consistent with the very high $\mathrm{U} / \mathrm{Th}, \mathrm{Pb} / \mathrm{Ce}$ and $\mathrm{Sr} / \mathrm{Nd}$ of the inclusion parental melts in this study ${ }^{50}$ (Fig. 4a and Supplementary Table 13). Mixing models show that the high $S$ contents and $\delta^{34} S$ in MP (i.e., representative of the composition of the volatile fraction dissolved in their parental melts, Fig. 4b) require the involvement of subducted serpentinite-derived agents carrying $\geq 1000$ p.p.m. S as sulfate (with an assumed $\delta^{34} S$ of $14.5 \%$ in the original agents ${ }^{15}$ ). Therefore, high $S, S^{6+} / \Sigma S$ and $\delta^{34} S$ in melts percolating through the mantle below the Kamchatka and West Bismarck arcs must result predominantly from the addition of Srich, oxidised slab agents to their depleted source protoliths in the mantle wedge (Fig. 1b). As the results in this study link the presence of sulfate recycled from the slab and elevated $\delta^{34} S$ in sub-arc mantle melts, by extension, they also support the idea that high $\delta^{34} S$ in primitive, un-degassed lavas from global arcs ${ }^{19-21,51}$ (Fig. 1b) can serve as a reliable proxy for the presence of oxidising slab agents in their mantle wedge sources.

The lower-bound $\Delta \log f \mathrm{O}_{2}$ inferred for the MP in this study (ca., FMQ + 1, Fig. 1a) precisely corresponds to previous 
estimates based on the $\mathrm{Fe}^{3+} / \sum \mathrm{Fe}$ in spinel from primitive arc lavas ${ }^{11}$. In this context, it is interesting to note that the major element compositions of the original parental melts of MP and vein MI (respectively, magnesian andesite ${ }^{28}$ and high-Ca boninite $^{29}$ ) are close to those of mantle-derived liquids typically found at subduction zones, whereas LT inclusions rather resemble lowtemperature hydrous melts produced in partial melting experiments of slab rock analogues ${ }^{52,53}$ (Supplementary Table 1). This dichotomy in the apparent origins of the inclusion parental melts is directly illustrated by the variable $\mathrm{Mg} \#$ of their glasses, which are close to those for melts in equilibrium with the mantle in MP and vein MI but much lower in LT inclusions (Supplementary Table 1). Note that, as variations in the $\mathrm{Mg} \#$ of spinel next to these inclusions are very limited (Supplementary Tables 5 and 8), it is improbable that this parameter was significantly modified in the included melts by post-entrapment processes (e.g., reequilibration through solid-state diffusion in spinel). Therefore, the results in this study suggest that slab agents transporting recycled sulfate ions can not only maintain their oxidising capacity during kilometre-scale percolation in the mantle wedge, but this oxidised sulfur can be effectively transferred to primitive arc magmas during mantle melting (Fig. 1b).

Considering the percolated harzburgite samples in this study, their calculated equilibrium $\mathrm{fO}_{2}$ fits within the upper range previously reported for sub-arc mantle peridotites ${ }^{13,34}$ (Fig. 1a). Recently, elevated $\Delta \log \mathrm{O}_{2}$ and orthopyroxene contents in $\mathrm{SiO}_{2}{ }^{-}$ rich, sub-arc mantle harzburgite xenoliths have been both related to fluxed melting processes involving oxidised slab agents during their formation ${ }^{26,34}$. In this study, it is shown that $\geq 1000$ p.p.m. of sulfate from subducted serpentinite can contribute to the volatile fraction in the mantle-derived parental melts of MP (Fig. 4b), while $\mathrm{SiO}_{2}$-rich liquids resembling hydrous slab melts in LT inclusions contain $\sim 3400$ p.p.m. sulfate on average (Supplementary Table 1). On the one hand, a $\mathrm{SiO}_{2}$-rich melt is required to explain the generation of an orthopyroxene-rich sub-arc mantle through the reaction:

$$
\text { Olivine }+\mathrm{SiO}_{2}<=>\text { orthopyroxene }
$$

during fluxed melting ${ }^{26}$. On the other hand, 3000 p.p.m. sulfate are required to elevate $\Delta \log f \mathrm{O}_{2}$ from $\mathrm{FMQ}-0.5$ to $\mathrm{FMQ}+1.5$ through reaction (1) in a primary melt containing $~ 10 \mathrm{wt} \%$ total $\mathrm{FeO}$ (ref. ${ }^{15}$ ). An elevation of $\Delta \log \mathrm{fO}_{2}$ from FMQ-0.5 to FMQ + 1.5 overlaps with the shift between the average upper-bound oxidation states recorded in abyssal and sub-arc mantle peridotites, respectively $13,34,43,44$ (Fig. 1a).

Detailed characterisation of the percolated harzburgite samples in this study allows further insights into melt-rock interaction processes occurring in the sub-arc mantle. Ionov et al. ${ }^{28}$ originally attributed the formation of LT inclusions and MP to the pervasive percolation of 'exotic' melts in the sub-arc mantle lithosphere. This is in line with the generally $\left(\mathrm{Cr}, \mathrm{Fe}^{3+}, \mathrm{Fe}^{2+}\right)$-rich nature of spinel in the percolated harzburgite samples, in comparison with those recognised as 'pristine' residues and found at the same sampling sites ${ }^{25-29,34}$. The observation that the $\mathrm{Cr}, \mathrm{Fe}_{\mathrm{t}}$ and $\mathrm{Fe}^{3+} / \Sigma \mathrm{Fe}$ increase is sometimes restricted to the LT inclusionbearing rims of some spinel grains further shows that this mineral experienced oxidation because of reactions with sulfate-bearing melts originally percolating at grain boundaries (Supplementary Fig. 7 and Supplementary Table 5). Therefore, melt-peridotite interactions in the sub-arc mantle lithosphere have partially or entirely modified the chemistry of spinel grains, likely through dissolution and re-precipitation of this mineral (Supplementary Discussion). This process is consistent with the inferred redox equilibrium between the percolated harzburgite samples and the inclusion parental melts at $\Delta \log f \mathrm{O}_{2}$ ranging from $\mathrm{FMQ}+1$ to FMQ + 1.5 (Fig. 1a and Supplementary Discussion).

Melt-peridotite interactions in the sub-arc mantle lithosphere were constrained by diffusion to occur only several months before eruption in the case of some West Bismarck peridotite xenoliths from the same sampling sites as in this study ${ }^{37}$. However, it is unlikely that these timescales are short enough to fully prevent post-entrapment $\mathrm{Fe}^{2+}-\mathrm{Mg}$ re-equilibration between the included melts and spinel, for instance during cooling 54,55 . The small extent of this process, however, is traced by the presence of irregular halos with very limited variations in $\mathrm{Fe}^{2+}, \mathrm{Mg}$ and $\mathrm{Mg} \#$ around the inclusions in this study (Fig. 3d, Supplementary Tables 5, 6 and Discussion). The LT inclusions and MP analysed in this study do not contain daughter silicate phases; the former only host anhydrite and rare sulfides ${ }^{28}$ (Figs. 2, 3 and Supplementary Fig. 4). Therefore, if chemical variations in spinel halos are related to post-entrapment crystallisation from the inclusion parental melts, they can only involve these S-bearing phases. Simple chemical exchange reactions between a sulfate-bearing melt and spinel can be inferred from the variations in atomic concentrations within the EPMA profiles around the inclusions (Supplementary Tables 5, 6 and Discussion). From these exchange reactions, it appears that higher $\mathrm{Fe}^{3+} / \Sigma \mathrm{Fe}$ in the halos can only originate from the oxidation of small amounts of $\mathrm{Fe}^{2+}$ from the host spinel by $\mathrm{S}^{6+}$ present in the inclusion parental melts through reaction (1), or a similar one involving $\mathrm{H}_{2} \mathrm{SO}_{4}$ and FeS compounds (Supplementary Discussion). We conclude that the $\left(\mathrm{Cr}, \mathrm{Fe}^{3+}, \mathrm{Fe}^{2+}\right)$-rich nature of spinel in the percolated harzburgite samples, further substantiated by the presence of $\mathrm{Fe}^{3}$ ${ }^{+}$-rich halos, primarily traces $\mathrm{S}^{6+}-\mathrm{Fe}^{2+}$ redox coupling during melt-rock interactions within the sub-arc mantle lithosphere. Therefore, it is directly shown in this study that sub-arc mantle oxidation can proceed during melt-rock interactions involving $\mathrm{SiO}_{2}$-rich and $\mathrm{S}^{6+}$-bearing melts (Fig. 3d \& Supplementary Fig. 7). These observations, made here in xenoliths from the subarc mantle lithosphere, provide an analogue for the fluxed melting reactions typically occurring throughout the mantle wedge 26,34 (Fig. 1b).

Melt-rock interactions involving $\mathrm{S}^{6+}-\mathrm{Fe}^{2+}$ redox coupling can eventually lead to the formation of sulfide species according to reaction (1) (Supplementary Figs 2-4, 6 and 7). These sulfides, when present as an immiscible phase in LT inclusions, are typically enriched in $\mathrm{Cu}$ at the contact with the enclosed, sulfate-bearing silicate melts (Supplementary Fig. 4 and Supplementary Table 4), which is consistent with the composition of sulfides formed at high $\mathrm{fO}_{2}$ in experiments ${ }^{56}$. This compositional feature of sulfides trapped in the inclusions contrasts with those found disseminated in the host spinel harzburgite, which are dominated by $(\mathrm{Fe}, \mathrm{Ni})$-bearing mono-sulfide solid solution, pyrrhotite and pentlandite species with systematically $<1 \mathrm{wt} \% \mathrm{Cu}\left(\right.$ ref. ${ }^{57}$ ). A similar metal enrichment process in sulfides formed under oxidised conditions has been suggested for some other precious metals such as gold ${ }^{58}$. Therefore, our results provide in situ evidence for the role of oxidised conditions in the concentration of metals of economic interest in immiscible, $S^{2-}$-bearing phases at subduction zones.

Overall, as this study directly documents the oxidised nature of melts from the Kamchatka and West Bismarck arcs at mantle conditions (Fig. 1b), it rules out melt differentiation in the arc crust as a cause for this oxidation. Instead, slab-derived sulfate originating from $\delta^{34} \mathrm{~S}$ - and $(\mathrm{U}, \mathrm{Pb}, \mathrm{Sr})$-rich subducted serpentinites $^{15,50}$ is demonstrated to be a potentially oxidising agent added to mantle wedge magma sources. Inevitably, this implies that slab agents can maintain their oxidising capacity during migration through the lower mantle wedge (Fig. 1b), and hence they are able to deliver oxidised volatile species to the source regions of arc magmas and affect the 'redox budget' in subduction zones. 


\section{Methods}

XRF maps and XANES. XRF maps and XANES spectra at the S K-edge were collected at the European Synchrotron Radiation Facility (ESRF; Grenoble, France) using the scanning X-ray microscope of the ID21 beamline and a micro-focused beam. The beamline uses a $\mathrm{Si}$ (111) double-crystal mono-chromator and the energy was calibrated to the position of the white line of gypsum $(2482.94 \mathrm{eV})$. The incident beam intensity was measured using a photodiode. All measurements were performed in fluorescence mode with a focused beam of $0.4 \times 0.8 \mu \mathrm{m}$ because of the small size of most of the melt inclusions $(\leq 50 \mu \mathrm{m})$ investigated in this study. A focussed beam in combination with a high photon flux may cause damage to the sulfur-bearing glass samples, generating $\mathrm{S}^{4+}$ by photo-reduction ${ }^{59-61}$. In order to minimise the focussed beam damage, an attenuator of $\mathrm{Al}$ foil with $6 \mu \mathrm{m}$ thickness was applied to reduce the incident flux on the sample. Before each XANES measurement, the melt inclusion was localised within the spinel by simultaneous $\mathrm{Si}, \mathrm{Al}$ and S Ka XRF imaging with step sizes of 1 or $2 \mu \mathrm{m}$ and counting times of $1 \mathrm{~s}$ per step. Results of the S Ka X-ray maps are shown in Fig. 2 and Supplementary Fig. 5.

The XANES spectra were acquired by continuously scanning the monochromator and changing the gap of the undulator with a step size of $0.23 \mathrm{eV}$. One to 10 quick scans (with the acquisition time fixed at $0.1 \mathrm{~s}$ per energy step) were collected and stacked to reduce signal-to-noise ratio. The background of the spectra was subtracted by fitting the energy region below the edge with a quadratic function and subtracting this from the spectra. The edge jump was normalised to unity by fitting an arctangent and a Gaussian function to the spectra. The $S^{6+} / \Sigma S$ was calculated using integrated intensities collected on energy windows corresponding to $\mathrm{S}^{2-}$ and $\mathrm{S}^{6+}$ following the method of Jugo et al. ${ }^{8}$ and Wilke et al. ${ }^{60}$. The XANES spectra and calculated $S^{6+} / \Sigma S$ are shown in Fig. 2 and Supplementary Fig. 5, and given in Supplementary Table 1.

Raman spectrometry. Raman spectra were collected with a Renishaw microRaman spectrometer (RM-1000) using the $532 \mathrm{~nm}$ line of a Nd:YAG laser at the Goethe University (Frankfurt am Main, Germany) ${ }^{61}$. The spectrometer was equipped with a Leica DMLM optical microscope and a Peltier-cooled, chargecoupled device detector. All spectra were collected from polished $(\sim 120 \mu \mathrm{m}$ thick $)$ sections and separated spinel grains mounted into epoxy in the wavenumber range $100-3000 \mathrm{~cm}^{-1}$. The spectral resolution was $2 \mathrm{~cm}^{-1}$ and a quasi-backscattering geometry was employed. Exposure times were $60 \mathrm{~s}$ with the laser power fixed at $10-20 \%$. No effect of laser beam exposure (i.e., beam damage) on the qualitative results were observed with these analytical conditions; for instance, only variations in signal-to-noise ratio are observed for lower acquisition times. The system was calibrated using the $519 \mathrm{~cm}^{-1}$ band of a silicon wafer ${ }^{62}$. The calibration was checked with a Ne lamp ${ }^{63}$. The wavenumber accuracy was around $\sim 1 \mathrm{~cm}^{-1}$. The Raman spectra are shown in Figs. 2, 3 and Supplementary Fig. 6 with the compositions of the investigated inclusions given in Supplementary Tables 1-3.

EPMA analyses of the inclusion glasses. The major element compositions and sulfur contents of the inclusion glasses were determined by EPMA at the Research School of Earth Sciences (RSES) of the Australian National University (ANU; Canberra, Australia). The instrument used was a Cameca SX 100 operating at an accelerating voltage of $15 \mathrm{kV}$, defocused beams of $5-20 \mu \mathrm{m}$ in diameter and reduced beam currents of 2-10 nA. Counting times were 5-10 s on background and $20-30 \mathrm{~s}(\mathrm{Cr}$ and $\mathrm{Ni}), 15 \mathrm{~s}(\mathrm{Ca}$ and $\mathrm{Ti})$ and $10 \mathrm{~s}$ for all other elements on peaks, with $\mathrm{Na}$ and $\mathrm{K}$ analysed first. Sulfur was independently analysed in peak integral mode using three spectrometers (respectively with a pentaerythritol and two large pentaerythritol crystals), with increased sample currents and counting times. Matrix effects were corrected using the Phi (r) z modelling available on Peak Sight ${ }^{\odot}$ software from Cameca ${ }^{\mathrm{TM}}$.

These analytical conditions allowed minimising alkali metal losses and/or migration from the analysed area; this setup was previously used to report $\mathrm{Na}_{2} \mathrm{O}$ concentrations of up to $6 \mathrm{wt} \%$ in Kamchatka sub-arc mantle $\mathrm{MI}^{28,29}$. In addition, this setup has been previously demonstrated to provide deficiency of totals of analyses in good agreement with SIMS volatile data ${ }^{29}$.

EPMA and SEM imaging and mapping. EPMA and SEM maps and quantitative analyses were respectively acquired at RSES and the Centre for Advance Microscopy at ANU. The instruments used were the Cameca SX 100 (EPMA, operating at an accelerating voltage of $15 \mathrm{kV}$ and a beam current of $40 \mathrm{nA}$ ) and a Schottky Field Emission Hitachi 4300 SE/N (SEM, operating at the same conditions as the EPMA).

EPMA analyses of spinel with Mössbauer standards. The $\mathrm{Fe}^{3+} / \Sigma \mathrm{Fe}$ of spinel was determined by EPMA at the Goethe University using a set of secondary spinel standards following the procedure outlined by Wood and Virgo ${ }^{4}$. The analyses were performed with a JXA-8900 superprobe, using six spinel standards for which $\mathrm{Fe}^{3+} / \Sigma \mathrm{Fe}$ had been previously determined by Mössbauer spectroscopy by Wood \& $\mathrm{Virgo}^{4}$. Measurements were conducted with an accelerating voltage of $15 \mathrm{kV}$, a $\sim 3$ $\mu \mathrm{m}$ spot diameter and a beam current of $20 \mathrm{nA}$. Data were collected with normal counting times of 15-40 s on backgrounds and 20-40 s on peaks (depending on the element considered). In this study, corrections to the $\mathrm{Fe}^{3+} / \Sigma \mathrm{Fe}$ calculated by stoichiometry were small and ranged from 0 to -0.02 (i.e., overestimated value).
The error on the corrected $\mathrm{Fe}^{3+} / \Sigma \mathrm{Fe}$ in spinel is \pm 0.025 . The corrected $\mathrm{Fe}^{3+} / \Sigma \mathrm{Fe}$ in sample spinel are displayed in Supplementary Tables 5 and 6, whereas standard analyses during EPMA runs are given in Supplementary Table 7.

Sulfur isotope measurements. The $S$ isotope compositions $\left(\delta^{34} S_{\text {measured }}\right.$, see below for usage of delta notation) of the MP were determined by SIMS using the Cameca IMS 1280 (mono-collector) of the Northeast National Ion Microprobe Facility (NENIMF) at Woods Hole Oceanographic Institution (WHOI; USA). The measurements were conducted using a $10 \mu \mathrm{m} \mathrm{Cs}^{+}$primary beam, an accelerating voltage of $10 \mathrm{kV}$ and a beam current of $1-2 \mathrm{nA}$. The secondary ions were collected at an accelerating voltage of $10 \mathrm{kV}$, with a $150 \mu \mathrm{m}$ field of view and a mass resolution power (MRP; $M / \Delta M$ ) of $4000-5500$, using an electron multiplier. The energy slit was centred and opened to $40-60 \mathrm{~V}$. Each measurement consisted of fifty cycles for ${ }^{32} \mathrm{~S}$ and ${ }^{34} \mathrm{~S}$, respectively. By operating the Cameca IMS 1280 at a MRP of 5500, it becomes possible to avoid interferences from ${ }^{31} \mathrm{P}^{1} \mathrm{H}$ with ${ }^{32} \mathrm{~S}$ (ref. ${ }^{64}$ ). With this analytical setup, in situ $\delta^{34} \mathrm{~S}$ measurements on a $15 \times 15 \mu \mathrm{m}$ area can be conducted with a precision of $0.4-0.6 \%$ in silicate glasses containing about $500-1600$ p.p.m. S (ref. ${ }^{64}$ ), i.e., overlapping the range measured in the MP in this study (Supplementary Tables 1 and 11).

The SIMS analysis is based on the measurement of S-bearing glass standards with known $\mathrm{S}$ isotope composition to account for the instrumental mass fractionation (IMF) ${ }^{65}$. In-house glass standards at WHOI with major element compositions ranging from basaltic to $\mathrm{SiO}_{2}$-rich glasses were used for this calibration ${ }^{65}$. The $\mathrm{S}$ isotope composition of these glass standards $\left(\delta^{34} \mathrm{~S}_{\text {true }}\right)$ covers a range from about $-5.3 \%$ up to about $+12 \%$ and was typically determined by KIBA reagent extraction method or calculated on the basis of the isotope composition of the source of S used for the glass syntheses. The nearly 1:1 linear correlation between the KIBA and SIMS results reported earlier ${ }^{65}$ confirms the high analytical accuracy of the independent determination of $\delta^{34} S_{\text {true. }}$

The $y$ axis intercept of the linear correlation between KIBA and SIMS results reflects the IMF, which was typically ranging between 0.9935 and 0.995 during our analytical session (Supplementary Table 11). The nearly 1:1 correlation also indicates that the IMF is largely independent of matrix effects related to bulk glass compositions (i.e., major elements and $\delta^{34} S$ ) within the ranges defined by the standards ${ }^{65}$. In addition, variations in the $S$ valence state in silicate glasses are not expected to produce a detectable IMF. This is because the energy involved in the sputtered ion formation process $(10-12 \mathrm{keV})$ completely overwhelms the bond energies in silicate glasses, as was demonstrated by $\delta^{34} S$ recently determined on experimental glasses equilibrated at variable $f_{2}$ (ref. ${ }^{65}$ ).

Correction and filtering of the raw SIMS data (to give $\left({ }^{34} \mathrm{~S} /{ }^{32} \mathrm{~S}\right)$ corrected) were realised to account for the variations of IMF during a 50-cycles measurement. In order to monitor short- and long-term variations of IMF and to allow a correction of the raw $\delta^{34} \mathrm{~S}$, at least two measurements on a selected standard (JDF $46^{\circ} \mathrm{N}$ basaltic glass) were conducted every 2-3 unknown samples (Supplementary Table 11). The $\delta^{34} S_{\text {measured }}$ were then calculated relative to the Vienna Canyon Diablo Troilite (V-CDT) isotope reference standard as follows:

$$
\delta^{34} \mathrm{~S}_{\text {measured }}=\left(\left({ }^{34} \mathrm{~S} /{ }^{32} \mathrm{~S}\right)_{\text {corrected }} / \mathrm{IMF} / 0.04416375-1\right) \times 1000
$$

where 0.04416375 is the ${ }^{34} \mathrm{~S} /{ }^{32} \mathrm{~S}$ for $\mathrm{V}$-CDT having $\delta^{34} \mathrm{~S}=0 \%$. The $2 \sigma$ errors associated with the $\delta^{34} S_{\text {measured }}$ in this study $(0.6-1.6 \%$, Supplementary Table 11$)$ were propagated from the signal count statistics and the uncertainty in the regression of the SIMS calibration curve. Recent replicate analyses of a MORB glass standard (892-1) have revealed an external reproducibility of SIMS analysis of \pm $0.52 \% 0(n=13,2 \sigma)^{65}$. More detail on SIMS calibration materials for in situ S isotope analyses of silicate glasses and the processing procedures of raw SIMS data can be found in Fiege et al. ${ }^{65}$.

\section{Data availability}

The authors declare that the data generated or analysed during this study are included in this published article and its Supplementary Information files.

Received: 8 August 2017 Accepted: 24 July 2018 Published online: 29 August 2018

\section{References}

1. Giggenbach, W. F. Magma degassing and mineral deposition in hydrothermal systems along convergent plate boundaries. Econ. Geol. 87, 1927-1944 (1992).

2. Tomkins, A. G. \& Evans, K. A. Separate zones of sulfate and sulfide release from subducted mafic oceanic crust. Earth. Planet. Sci. Lett. 428, 73-83 (2015).

3. Kress, V. C. \& Carmichael, I. S. E. The compressibility of silicate liquids containing $\mathrm{Fe}_{2} \mathrm{O}_{3}$ and the effect of composition, temperature, oxygen fugacity and pressure on their redox states. Contrib. Mineral. Petrol. 108, 82-92 (1991). 
4. Wood, B. J. \& Virgo, D. Upper mantle oxidation state: ferric iron contents of lherzolite spinels by ${ }^{57} \mathrm{Fe}$ Mössbauer spectroscopy and resultant oxygen fugacities. Geochim. Cosmochim. Acta 53, 1277-1291 (1989).

5. Ballhaus, C., Berry, R. F. \& Green, D. H. High-pressure calibration of the olivine-orthopyroxene-spinel oxygen geobarometer: implications for the oxidation state of the upper mantle. Contrib. Mineral. Petrol. 107, 27-40 (1991).

6. Wallace, P. J. \& Carmichael, I. S. E. S speciation in submarine basaltic glasses as determined by measurements of $\mathrm{S} K \alpha \mathrm{X}$-ray wavelength shifts. Am. Min. 79, 161-167 (1994).

7. Rowe, M. C., Kent, A. J. R. \& Nielsen, R. L. Subduction influence on oxygen fugacity and trace and volatile elements in basalts across the Cascade volcanic arc. J. Petrol. 50, 61-91 (2009).

8. Jugo, P. J., Wilke, M. \& Botcharnikov, R. E. Sulfur K-edge XANES analysis of natural and synthetic basaltic glasses: Implications for $\mathrm{S}$ speciation and $\mathrm{S}$ content as function of oxygen fugacity. Geochim. Cosmochim. Acta 74, 5926-5938 (2010).

9. Wood, B. J., Bryndzia, L. T. \& Johnson, K. E. Mantle oxidation state and its relationship to tectonic environment and fluid speciation. Science $\mathbf{2 4 8}$, 337-345 (1990).

10. Carmichael, I. S. E. The redox states of basic and silicic magmas: a reflection of their source regions? Contrib. Mineral. Petrol. 106, 129-141 (1991).

11. Evans, K. A., Elburg, M. A. \& Kamenetsky, V. S. Oxidation state of sub-arc mantle. Geology 40, 783-786 (2012).

12. Brandon, A. D. \& Draper, D. S. Constraints on the origin of the oxidation state of mantle overlying subduction zones: an example from Simcoe, Washington, USA. Geochim. Cosmochim. Acta 60, 1739-1749 (1996).

13. Parkinson, I. J. \& Arculus, R. J. The redox state of subduction zones: insights from arc-peridotites. Chem. Geol. 160, 409-423 (1999).

14. Kelley, K. A. \& Cottrell, E. Water and the oxidation state of subduction zone magmas. Science 325, 605-607 (2009).

15. Alt, J. C. et al. Recycling of water, carbon, and sulfur during subduction of serpentinites: a stable isotope study of Cerro del Almirez, Spain. Earth. Planet. Sci. Lett. 327, 50-60 (2012).

16. Klimm, K., Kohn, S. C. \& Botcharnikov, R. E. The dissolution mechanism of sulphur in hydrous silicate melts. II: solubility and speciation of sulphur in hydrous silicate melts as a function of $\mathrm{fO}_{2}$. Chem. Geol. 322-323, 250-267 (2012).

17. Debret, B. et al. Isotopic evidence for iron mobility during subduction. Geology 44, 215-218 (2016).

18. Pons, M.-L., Debret, B., Bouilhol, P., Delacour, A. \& Williams, H. Zinc isotope evidence for sulfate-rich fluid transfer across subduction zones. Nat. Commun. 7, 13794 (2016).

19. Alt, J. C., Shanks, W. C. III \& Jackson, M. C. Cycling of sulfur in subduction zones: the geochemistry of sulfur in the Mariana Island Arc and back-arc trough. Earth. Planet. Sci. Lett. 119, 477-494 (1993).

20. de Moor, J. M. et al. Sulfur degassing at Erta Ale (Ethiopia) and Masaya (Nicaragua) volcanoes: Implications for the degassing processes and oxygen fugacities of basaltic systems. Geochem. Geophys. Geosyst. 14, 4076-4108 https://doi.org/10.1002/ggge.20255 (2013).

21. Kagoshima, T. et al. Sulphur geodynamic cycle, Sci. Rep. 5, 8330 https://doi. org/10.1038/srep08330 (2015).

22. Lee, C.-T. A., Leeman, W. P., Canil, D. \& Li, Z.-X. A. Similar V/Sc systematics in MORB and arc basalts: Implications for the oxygen fugacities of their mantle source regions. J. Petrol. 46, 2313-2336 (2005).

23. Lee, C.-T. A. et al. The redox state of arc mantle using $\mathrm{Zn} / \mathrm{Fe}$ systematics. Nature 468, 681-685 (2010).

24. Lee, C.-T. A. et al. Copper systematics in arc magmas and implications for crust-mantle differentiation. Science 336, 64-68 (2012).

25. Ionov, D. A. Petrology of mantle wedge lithosphere: new data on suprasubduction zone peridotite xenoliths from the andesitic Avacha volcano, Kamchatka. J. Petrol. 51, 327-361 (2010).

26. Bénard, A., Arculus, R. J., Nebel, O., Ionov, D. A. \& McAlpine, S. R. B. Silicaenriched mantle sources of subalkaline picrite-boninite-andesite island arc magmas. Geochim. Cosmochim. Acta 199, 287-303 (2017).

27. Tollan, P. M. E., Dale, C. W., Hermann, J., Davidson, J. P. \& Arculus, R. J. Generation and modification of the mantle wedge and lithosphere beneath the West Bismarck island arc: melting, metasomatism and thermal history of peridotite xenoliths from Ritter island. J. Petrol. 58, 1475-1510 (2017).

28. Ionov, D. A., Bénard, A. \& Plechov, P. Y. Melt evolution in subarc mantle: evidence from heating experiments on spinel-hosted melt inclusions in peridotite xenoliths from the andesitic Avacha volcano (Kamchatka, Russia). Contrib. Mineral. Petrol. 162, 1159-1174 (2011).

29. Bénard, A. et al. Primary silica-rich picrite and high-Ca boninite melt inclusions in pyroxenite veins from the Kamchatka sub-arc mantle. J. Petrol. 57, 1955-1982 (2016).

30. Bénard, A., Ionov, D. A., Shimizu, N. \& Plechov, P. Y. The volatile content of subduction zone melts and fluids. Min. Mag. 75, 513 (2011).
31. Bénard, A., Shimizu, N., Klimm, K., Ionov, D. A. \& Plechov, P. Y. Volatile content, $\mathrm{S}$ partitioning, speciation and isotopes in the mantle wedge. Eur. Mineral. Conf. 1, 582-583 (2012). EMC2012.

32. Mallmann, G. \& O’Neill, H. St. C. The crystal/melt partitioning of V during mantle melting as a function of oxygen fugacity compared with some other elements (Al, P, Ca, Sc, Ti, Cr, Fe, Ga, Y, Zr and Nb). J. Petrol. 50, 1765-1794 (2009).

33. Gaetani, G. A., O’Leary, J. A., Shimizu, N., Bucholz, C. E. \& Newville, M. Rapid reequilibration of $\mathrm{H}_{2} \mathrm{O}$ and oxygen fugacity in olivine-hosted melt inclusions. Geology 40, 915-918 (2012).

34. Bénard, A., Woodland, A. B., Arculus, R. J., Nebel, O. \& McAlpine, S. R. B. Variation in sub-arc mantle oxygen fugacity during partial melting recorded in refractory peridotite xenoliths from the West Bismarck Arc. Chem. Geol. 486, 16-30 (2018)

35. Demouchy, S. \& Mackwell, S. Mechanisms of hydrogen incorporation and diffusion in iron-bearing olivine. Phys. Chem. Miner. 33, 347-355 (2006).

36. Bromiley, G. D., Brooke, J. \& Kohn, S. C. Hydrogen and deuterium diffusion in non-stochiometric spinel. High. Press. Res. 37, 360-376 (2017).

37. Tollan, P. M. E., O’Neill, H. St. C., Hermann, J., Benedictus, A. \& Arculus, R. J. Frozen melt-rock reaction in a peridotite xenolith from sub-arc mantle recorded by diffusion of trace elements and water in olivine. Earth. Planet. Sci. Lett. 422, 169-181 (2015).

38. Demouchy, S., Jacobsen, S. D., Gaillard, F. \& Stern, C. R. Rapid magma ascent recorded by water diffusion profiles in mantle olivine. Geology 34, 429-432 (2006).

39. Moretti, R. \& Baker, D. R. Modeling the interplay of $f \mathrm{O}_{2}$ and $f \mathrm{~S}_{2}$ along the FeSsilicate melt equilibrium. Chem. Geol. 256, 286-298 (2008).

40. Matjuschkin, V., Blundy, J. D. \& Brooker, R. A. The effect of pressure on sulphur speciation in mid- to deep-crustal arc magmas and implications for the formation of porphyry copper deposits. Contrib. Mineral. Petrol. 171, 66-90 (2016).

41. Cottrell, E. \& Kelley, K. A. The oxidation state of Fe in MORB glasses and the oxygen fugacity of the upper mantle. Earth. Planet. Sci. Lett. 305, 270-282 (2011).

42. Berry, A. J., Stewart, G. A., O’Neill, H. St. C., Mallmann, G. \& Mosselmans, J. F. W. A re-assessment of the oxidation state of iron in MORB glasses. Earth. Planet. Sci. Lett. 483, 114-123 (2018).

43. Bryndzia, L. T. \& Wood, B. J. Oxygen thermobarometry of abyssal spinel peridotites: The redox state and C-O-H volatile composition of the Earth's sub-oceanic upper mantle. Am. J. Sci. 290, 1093-1116 (1990).

44. Birner, S. K., Cottrell, E., Warren, J. M., Kelley, K. A. \& Davis, F. A. Peridotites and basalts reveal broad congruence between two independent records of mantle $\mathrm{fO}_{2}$ and despite local redox heterogeneity. Earth. Planet. Sci. Lett. 494, 172-189 (2018).

45. Canil, D. et al. Ferric iron in peridotites and mantle oxidation states. Earth. Planet. Sci. Lett. 123, 205-220 (1994).

46. Salters, V. J. M. \& Stracke, A. Composition of the depleted mantle. Geochem Geophys. Geosyst. 5, https://doi.org/10.1029/2003GC000597 (2004).

47. Mavrogenes, J. A. \& O’Neill, H. St. C. The relative effects of pressure, temperature and oxygen fugacity on the solubility of sulfide in mafic magmas. Geochim. Cosmochim. Acta 63, 1173-1180 (1999).

48. Labidi, J., Cartigny, P., Birck, J. L., Assayag, N. \& Bourrand, J. J. Determination of multiple sulfur isotopes in glasses: a reappraisal of the MORB $\delta^{34} \mathrm{~S}$. Chem. Geol. 334, 189-198 (2012).

49. Labidi, J., Cartigny, P., Hamelin, C., Moreira, M. \& Dosso, L. Sulfur isotope budget $\left({ }^{32} \mathrm{~S},{ }^{33} \mathrm{~S},{ }^{34} \mathrm{~S}\right.$ and $\left.{ }^{36} \mathrm{~S}\right)$ in Pacific-Antarctic ridge basalts: a record of mantle source heterogeneity and hydrothermal sulfide assimilation. Geochim. Cosmochim. Acta 133, 47-67 (2014).

50. Deschamps, F., Godard, M., Guillot, S. \& Hattori, K. Geochemistry of subduction zone serpentinites: A review. Lithos 178, 96-127 (2013).

51. de Hoog, J. C. M., Taylor, B. E. \& van Bergen, M. J. Sulfur isotope systematics of basaltic lavas from Indonesia: implications for the sulfur cycle in subduction zones. Earth. Planet. Sci. Lett. 189, 237-252 (2001).

52. Prouteau, G., Scaillet, B., Pichavant, M. \& Maury, R. Evidence for mantle metasomatism by hydrous silicic melts derived from subducted oceanic crust. Nature 410, 197-200 (2001).

53. Kessel, R., Schmidt, M. W., Ulmer, P. \& Pettke, T. Trace element signature of subduction-zone fluids, melts and supercritical liquids at $120-180 \mathrm{~km}$ depth. Nature 437, 724-727 (2005).

54. Kamenetsky, V. S., Crawford, A. J. \& Meffre, S. Factors controlling chemistry of magmatic spinel: an empirical study of associated olivine, $\mathrm{Cr}$-spinel and melt inclusions from primitive rocks. J. Petrol. 42, 655-671 (2001).

55. Nikolaev, G. S., Ariskin, A. A. \& Barmina, G. S. SPINMELT-2.0: simulation of spinel-melt equilibrium in basaltic systems under pressures up to $15 \mathrm{kbar}$ : I. Model formulation, calibration, and tests. Geochem. Int. 56, 24-45 (2018).

56. Wohlgemuth-Ueberwasser, C. C., Fonseca, R. O. C., Ballhaus, C. \& Berndt, J. Sulfide oxidation as a process for the formation of copper-rich magmatic sulfides. Miner. Depos. 48, 115-127 (2013). 
57. Bénard, A. \& Ionov, D. A. PGE and trace elements in veined sub-arc mantle xenoliths, Avachinsky volcano, Kamchatka. Geochim. Cosmochim. Acta 74, A76 (2010)

58. Botcharnikov, R. E. et al. High gold concentrations in sulphide-bearing magma under oxidizing conditions. Nat. Geosci. 4, 112-115 (2011).

59. Wilke, M. et al. The origin of $\mathrm{S}^{4+}$ detected in silicate glasses by XANES. Am. Min. 93, 235-240 (2008)

60. Wilke, M., Klimm, K. \& Kohn, S. C. Spectroscopic studies on sulfur speciation in synthetic and natural glasses. Rev. Mineral. Geochem. 73, 41-78 (2011).

61. Klimm, K., Kohn, S. C., O’Dell, L. A., Botcharnikov, R. E. \& Smith, M. E. The dissolution mechanism of sulphur in hydrous silicate melts. I: assessment of analytical techniques in determining the sulphur speciation in iron-free to iron-poor glasses. Chem. Geol. 322-323, 237-249 (2012).

62. Temple, P. A. \& Hathaway, C. E. Multiphonon Raman-spectrum of silicon. Phys. Rev. B 7, 3685-3697 (1973).

63. Bayarjargal, L., Shumilova, T. G., Friedrich, A. \& Winkler, B. Diamond formation from $\mathrm{CaCO}_{3}$ at high pressure and temperature. Eur. J. Mineral. 22, 29-34 (2010).

64. Mandeville, C. W., Shimizu, N., Kelley, K. A. \& Cheek, L. Sulfur isotope variation in basaltic melt inclusions from Krakatau revealed by a newly developed secondary ion mass spectrometry technique for silicate glasses. EOS Trans. AGU 83, V-13-F07 (2008).

65. Fiege, A. et al. Sulfur isotope fractionation between fluid and andesitic melt: an experimental study. Geochim. Cosmochim. Acta 142, 501-521 (2014).

66. McDonough, W. F. \& Sun, S.-S. The composition of the Earth. Chem. Geol. 120, 223-253 (1995).

67. Saal, A. E., Hauri, E. H., Langmuir, C. H. \& Perfit, M. R. Vapour undersaturation in primitive mid-ocean-ridge basalt and the volatile content of Earth's upper mantle. Nature 419, 451-455 (2002).

\section{Acknowledgements}

We acknowledge financial support by the Australian Research Council (DE120100513 and DP120104240) and the ESRF for beam time (EC1061 and ES238). We acknowledge the ESRF for providing access to synchrotron radiation and the team ID21 for technical support. A.B. thanks L. Uenver-Thiele, R. Rapp and F. Brink for their assistance with Raman, EPMA and SEM, respectively. We thank Elizabeth Cottrell and Keiko Hattori for their constructive and helpful comments.

\section{Author contributions}

A.B. and K.K. originated the project and wrote the manuscript with contributions from A.B.W., R.J.A., M.W., R.E.B., O.N., N.S. and D.A.I. A.B. prepared the samples, collected Raman spectra, acquired EPMA and SEM data, performed Fe valence state measurements with A.B.W., sulfur isotope measurements with N.S. and all calculations reported in this article. K.K. collected XRF maps and XANES spectra with M.W., R.E.B. and C.R. Xenoliths from Avacha (Kamchatka arc) and Ritter (West Bismarck arc) volcanoes were provided by D.A.I. and R.J.A., respectively.

\section{Additional information}

Supplementary Information accompanies this paper at https://doi.org/10.1038/s41467 018-05804-2.

Competing interests: The authors declare no competing interests.

Reprints and permission information is available online at http://npg.nature.com/ reprintsandpermissions/

Publisher's note: Springer Nature remains neutral with regard to jurisdictional claims in published maps and institutional affiliations.

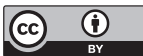

Open Access This article is licensed under a Creative Commons Attribution 4.0 International License, which permits use, sharing, adaptation, distribution and reproduction in any medium or format, as long as you give appropriate credit to the original author(s) and the source, provide a link to the Creative Commons license, and indicate if changes were made. The images or other third party material in this article are included in the article's Creative Commons license, unless indicated otherwise in a credit line to the material. If material is not included in the article's Creative Commons license and your intended use is not permitted by statutory regulation or exceeds the permitted use, you will need to obtain permission directly from the copyright holder. To view a copy of this license, visit http://creativecommons.org/ licenses/by/4.0/.

(c) The Author(s) 2018 